Research Article

\title{
Clinico-epidemiological Profile and Social Stigma in Hospitalised RT-PCR Confirmed COVID- 19 Cases with and without Comorbidity
}

\author{
Tamanna Nazli', Jugal Kishore ${ }^{2}$, Abdul Raheem $^{3}$, IsrarAhmad Ansari $^{4}$, Ajit Singh Ghai ${ }^{5}$, Heena $^{6}$ \\ ${ }^{1}$ Research Officer \& Unani Consultant, Unani Medical Centre, VMMC \& Safdarjung Hospital, New Delhi, India. \\ ${ }^{2}$ Director Professor, HoD, ${ }^{6}$ Statistician, Dept. of Community Medicine, VMMC \& Safdarjung Hospital, New Delhi, India. \\ ${ }^{3}$ Research Officer, Scientist-4, Central Council for Research in Unani Medicine, New Delhi, India. \\ ${ }^{4}$ Founder and Chairman, ${ }^{5}$ Consultant Physician, Ansari Hospital, Janakpuri, New Delhi, India. \\ DOI: https://doi.org/10.24321/2455.7048.202101
}

\section{I $\quad \mathbf{N} \quad \mathbf{F} \quad \mathbf{O}$}

\begin{abstract}
Corresponding Author:
Tamanna Nazli, Unani Medical Centre, VMMC \&

Safdarjung Hospital, New Delhi, India.

E-mail Id:

tamanna.ccrum@gmail.com

Orcid Id:

https://orcid.org/0000-0003-4517-3485

How to cite this article:

Nazli T, Kishore J, Raheem A, Ansari IA, Ghai AS, Heena. Clinico-epidemiological Profile and Social Stigma in Hospitalised RT-PCR Confirmed COVID-19 Cases with and without Comorbidity. Epidem Int. 2021;6(1):1-8.
\end{abstract}

Date of Submission: 2021-02-02

Date of Acceptance: 2021-03-19

\section{$\begin{array}{llllllll}\mathbf{A} & \mathbf{B} & \mathbf{S} & \mathbf{T} & \mathbf{R} & \mathbf{A} & \mathbf{C} & \mathbf{T}\end{array}$}

Introduction: The unprecedented COVID-19 outbreak has now spread to every nook of the world. It has contributed to an enormous adverse impact globally. Persons of every age group are likely to get infected but elderly people or those with comorbidities could develop a more serious illness.

Objectives: To describe the clinico-demographic characteristics, various risk factors, and COVID-19 related social stigma among 135 hospitalised patients in north India and to find an association by comparing it with comorbidity.

Methods: The present study is an observational analytical study carried out on 135 patients with RT-PCR confirmed cases admitted in a tertiary care hospital India aged between 15-79 years. Data were collected in a validated questionnaire specially designed for COVID-19 by National Centre for Disease Control (NCDC).

Result: A total of 135 patients were included (median age, 40 years [interquartile range $\{I Q R\}, 54-29$; range, $15-79$ years]; $62.9 \%$ Male). The presenting symptoms at the time of admission were fever (57.0\%), cough (43.0\%), fatigue (42.2\%), and breathlessness (28.1\%). The most prevalent comorbidities were hypertension (20\%), diabetes (14.1\%), thyroid disorder (6.7\%), cardiovascular diseases (3.7\%), and chronic obstructive pulmonary disease (4.4\%) and $23.7 \%$ patients reported having at least one comorbidity. Patients without pre-existing diseases have more social stigma as compared to patients with comorbidities. Twenty eight percent reported use of AYUSH therapies as prophylactic measures.

Conclusion: This study describes the clinico-demographic profile, baseline comorbidities, and social stigma associated with COVID-19 patients. Patients having comorbidity have less stigma, however, the family of both the groups were worried and supportive.

Keywords: COVID-19, RT-PCR, Comorbidity, Social Stigma, Coronavirus, AYUSH, Sars-CoV-2 


\section{Introduction}

Coronavirus Disease 2019 (COVID-19) is a new viral respiratory disease caused by the novel coronavirus (2019-nCoV), which has spread to almost every corner of the world. As of now, a total of 102,942,987 confirmed cases of COVID-19 infection have been identified in the world (updated on 30 April '21). In India, the prevalence of COVID-19 patients has increased significantly over the last few months and has now exceeded 18,762,976, making India the country with the second-highest number of COVID-19 cases. $^{1}$

People of any age with any underlying medical condition are at an increased risk for developing severe illness from COVID-19 such as malignancy, chronic kidney disease, serious heart conditions, COPD (chronic obstructive pulmonary disease), immunocompromised state (weakened immune system) from a solid organ transplant, obesity, hypertension, diabetes mellitus, and sickle cell disease. Previous studies show that COVID-19 patients with comorbidities may lead to a poor prognosis and may also be associated with a significantly increased risk of mortality. ${ }^{2,3}$

Patients' clinical manifestations included fever, nonproductive cough, fatigue, dyspnea, and myalgia. However, the difference in clinical characteristics between cases with and without comorbidity was not reported. Many study findings reported that the 2019-nCoV infection was more likely to affect older people with comorbidities, and could result in organ dysfunction (e.g., shock, Acute Respiratory Distress Syndrome [ARDS], acute cardiac injury, and acute kidney injury) and death. At present, there are no effective medicines or proven vaccine and treatment is just symptomatic. The objective of this study was to describe the clinical characteristics, identify various risk factors and the emotional response of 135 hospitalised patients with laboratory-confirmed RT-PCR positive reports, and to find their association with the patients having comorbidity and with those who did not have any pre-existing disease.

\section{Methods}

\section{Design and Setting}

This was an observational analytical hospital-based study carried out by the Department of Community Medicine on a sample of 135 patients with COVID-19 diagnosis confirmed with Reverse Transcriptase Polymerase Chain Reaction (RT-PCR) admitted in the Safdarjung Hospital, a dedicated tertiary care hospital for COVID-19 isolation and management in New Delhi, North India. The study is prepared according to the Strengthening the Reporting of Observational Studies in Epidemiology (STROBE) guidelines. Prior to data collection, the necessary approval was obtained from the Institutional Ethics Committee.
Data were collected from all the patients above 18 years who underwent testing for COVID-19 by RT-PCR from July to August 2020 to assess the association of comorbidity with an incidence of clinical manifestation, risk factors, and stigma in these confirmed COVID-19 patients. All the individuals who tested negative of COVID-19 in RT-PCR testing and suspected cases were excluded from the study.

\section{Study Participants}

Altogether 365 patients were screened and 145 patients, who tested positive for COVID-19 by RT-PCR were found eligible to take part in the study, of which 10 patients refused to participate in the trial, leaving a total of 135 patients. Informed consent from each participant was obtained and they were interviewed. The data was analysed by a research team initially from the medical record of patients, and detailed information was collected through phone calls. Each patient was explained the purpose of the study, and privacy and confidentiality were ensured, following which patient's queries regarding symptoms, treatment, and other doubts were taken before data collection.

\section{Sample Size and Sampling}

On the basis of a previous study, the prevalence of diabetes in COVID-19 patients was found to be $8.2 \%{ }^{3}$ Taking this value as reference, the minimum required sample size with a $5 \%$ margin of error and $5 \%$ level of significance is 116 patients.

\section{Study Tool}

Data was collected in a pre-tested validated questionnaire specially designed for screening of COVID-19 cases provided by the National Centre for Disease Control (NCDC) of the Ministry of Health \& Family Welfare, Government of India. The questionnaire captured information which included demographic data, signs, symptoms at the time of admission, comorbidities, travel history, exposure history, mechanism of contact, laboratory findings, treatment or prophylactic measures, and social stigma related questions. It took around 8-12 minutes to fill the questionnaire. ${ }^{4}$

\section{Statistical Analysis}

The data were entered in Microsoft Excel and were analysed using SPPS version 21.0. Descriptive statistics were used to characterise the study population. Association between categorical variables was assessed using Chi-Square test (or Fischer exact test). P-value $<0.05$ was considered significant.

\section{Result}

We reported the clinical characteristics of RT-PCR confirmed patients admitted to a COVID-19-dedicated hospital from north India. A total of 135 patients were included over a period between July to August 2020, with male preponderance $(n=85 ; 62.9 \%)$, mean age being $41.80 \pm 14.99$ 
years, and the median age being 40 years (IQR, 54-29; range, $15-79$ years). Forty Two (31.1\%) respondents were aged between 16 and 30 years of which majority were not having any pre-existing disease $(n=38 / 42 ; 90.5)$ in contrast to patients aged between 46 and 60 years where majority of the cases $(n=23 / 35 ; 65.7 \%)$ had known comorbidity (Table 1 ).

Table I.Demographic and Clinical Profile of Patients

\begin{tabular}{|c|c|c|c|c|}
\hline \multirow{2}{*}{ Variables } & \multicolumn{2}{|c|}{ Comorbidity n (\%) } & \multirow{2}{*}{ Chi-Square } & \multirow{2}{*}{ p-value } \\
\hline & Present $(n=50)$ & Absent $(n=85)$ & & \\
\hline \multicolumn{5}{|l|}{ Age (in years) } \\
\hline $15-30(n=43)$ & $5(11.6)$ & $38(88.4)$ & 17.469 & 0.001 \\
\hline $31-45(n=41)$ & $12(29.3)$ & $29(70.7)$ & 1.524 & 0.217 \\
\hline $46-60(n=35)$ & $23(65.7)$ & $12(34.3)$ & 16.663 & 0.001 \\
\hline$>60(n=16)$ & $10(62.5)$ & $6(37.5)$ & 5.047 & 0.025 \\
\hline \multicolumn{5}{|l|}{ Sex } \\
\hline Female $(n=50)$ & $25(50.0)$ & $25(50.0)$ & \multirow{2}{*}{5.722} & \multirow{2}{*}{0.017} \\
\hline Male $(n=85)$ & $25(29.41)$ & $60(70.59)$ & & \\
\hline \multicolumn{5}{|l|}{ Symptoms and signs at admission } \\
\hline Asymptomatic $(n=29)$ & $5(17.2)$ & $24(82.8)$ & 6.206 & 0.013 \\
\hline Fever $(n=77)$ & $31(40.3)$ & $46(59.7)$ & 0.798 & 0.372 \\
\hline Fatigue $(n=57)$ & $30(52.6)$ & $27(47.4)$ & 10.288 & 0.001 \\
\hline Cough $(n=58)$ & $25(43.1)$ & $33(56.9)$ & 1.605 & 0.205 \\
\hline Runny Nose $(n=14)$ & $4(28.6)$ & $10(71.4)$ & 0.480 & 0.488 \\
\hline Sore throat $(n=33)$ & $10(30.3)$ & $23(69.7)$ & 0.849 & 0.357 \\
\hline Breathlessness $(n=38)$ & $18(47.4)$ & $20(52.6)$ & 2.421 & 0.120 \\
\hline Diarrhoea $(n=6)$ & $2(33.3)$ & $4(66.7)$ & 0.037 & 0.848 \\
\hline Pain (muscular, chest, abdomen, joint) $(n=21)$ & $10(47.6)$ & $11(52.4)$ & 1.194 & 0.274 \\
\hline Nausea/ vomiting $(n=24)$ & $14(58.3)$ & $10(41.7)$ & 5.677 & 0.017 \\
\hline Headache $(n=36)$ & $19(52.8)$ & $17(47.2)$ & 5.216 & 0.022 \\
\hline Irritability/ confusion ( $n=7$ ) & $4(57.1)$ & $3(42.9)$ & 1.280 & 0.258 \\
\hline Redness of eyes $(n=6)$ & $4(66.7)$ & $2(33.3)$ & 2.364 & 0.124 \\
\hline Other symptoms $(n=10)$ & $7(70.0)$ & $3(30.0)$ & 5.032 & 0.025 \\
\hline Tachypnoea $(n=12)$ & $6(50.0)$ & $6(50.0)$ & 0.949 & 0.330 \\
\hline Abnormal lung auscultation $(n=12)$ & $7(58.3)$ & $5(41.7)$ & 2.562 & 0.109 \\
\hline Abnormal chest $X$ - Ray findings $(n=16)$ & $10(62.5)$ & $6(37.5)$ & 5.047 & 0.025 \\
\hline \multicolumn{5}{|l|}{ Travel history in past one month } \\
\hline Yes $(n=5)$ & $1(20.0)$ & $4(80.0)$ & & \multirow{2}{*}{0.421} \\
\hline No $(n=130)$ & $49(37.7)$ & $81(62.3)$ & & \\
\hline Contact history $(n=56)$ & $15(26.8)$ & $41(73.2)$ & 4.313 & 0.038 \\
\hline Prophylactic medication history $(n=85)$ & $33(38.8)$ & $52(61.2)$ & 1.232 & 1.232 \\
\hline \multicolumn{5}{|l|}{ Allopathic medicines } \\
\hline Multivitamins $(n=24)$ & $6(25.0)$ & $18(75.0)$ & 2.691 & 0.101 \\
\hline Vitamin C $(n=34)$ & $11(32.4)$ & $23(67.6)$ & 0.999 & 0.318 \\
\hline Hydroxychloroquine $(n=14)$ & $4(28.6)$ & $10(71.4)$ & 0.742 & 0.389 \\
\hline AYUSH medicines $(n=38)$ & $18(47.4)$ & $20(52.6)$ & 2.113 & 0.146 \\
\hline
\end{tabular}


Table 2.Response of Participants, Their Families, and Neighbours to COVID-I9 Positive Status

\begin{tabular}{|c|c|c|c|c|}
\hline \multirow{2}{*}{$\begin{array}{l}\text { Response of participants about their COVID-19 } \\
\text { positive status }\end{array}$} & \multicolumn{2}{|c|}{ Comorbidity n (\%) } & \multirow{2}{*}{$\begin{array}{l}\text { Chi- } \\
\text { Square }\end{array}$} & \multirow{2}{*}{ p-value } \\
\hline & Present $(n=50)$ & Absent $(n=85)$ & & \\
\hline Sad $(n=18)$ & $3(16.7)$ & $15(83.3)$ & 3.696 & $0.055^{*}$ \\
\hline Anxious ( $n=36$ ) & $15(41.7)$ & $21(58.3)$ & 0.451 & 0.502 \\
\hline Worried $(n=56)$ & $24(42.9)$ & $32(57.1)$ & 1.390 & 0.238 \\
\hline Denial $(n=10)$ & $4(40.0)$ & $6(60.0)$ & 0.041 & 0.840 \\
\hline Normal ( $n=16)$ & $4(25.0)$ & $12(75.0)$ & 1.128 & 0.288 \\
\hline Strong $(n=1)$ & $0(0.0)$ & $1(100.0)$ & 0.593 & 0.441 \\
\hline \multicolumn{5}{|l|}{$\begin{array}{c}\text { Response of family members to the COVID-19 } \\
\text { positive status of the patients }\end{array}$} \\
\hline Supportive $(n=65)$ & $26(40.0)$ & $39(60.0)$ & 0.472 & 0.492 \\
\hline Sad $(n=8)$ & $3(37.5)$ & $5(62.5)$ & 0.001 & 0.978 \\
\hline Worried $(n=45)$ & $16(35.6)$ & $29(64.4)$ & 0.064 & 0.801 \\
\hline Not informed $(n=7)$ & $1(14.3)$ & $6(85.7)$ & 1.639 & 0.200 \\
\hline \multicolumn{5}{|l|}{$\begin{array}{l}\text { Patients experience any discrimination or } \\
\text { changed attitude of family members }\end{array}$} \\
\hline Yes $(n=29)$ & $16(55.2)$ & $13(44.8)$ & 5.209 & $0.022^{*}$ \\
\hline No $(n=106)$ & $34(32.1)$ & 72 (67.9) & & \\
\hline \multicolumn{5}{|l|}{$\begin{array}{l}\text { Patients experience any discrimination or } \\
\text { changed attitude of their neighbours }\end{array}$} \\
\hline Yes $(n=71)$ & $31(43.7)$ & $40(56.3)$ & 2.819 & 0.093 \\
\hline No $(n=64)$ & $19(29.7)$ & $45(70.3)$ & & \\
\hline
\end{tabular}

Table 3.Contact History of RT-PCR Positive COVID- I9 Patients

\begin{tabular}{|c|c|c|c|c|}
\hline & \multicolumn{2}{|c|}{ Comorbidity n (\%) } & \multirow{2}{*}{$\begin{array}{l}\text { Chi- } \\
\text { Square }\end{array}$} & \multirow{2}{*}{ p-value } \\
\hline & Present $(n=50)$ & Absent $(n=85)$ & & \\
\hline H/ O contact with 2019-nCOV case $(n=56)$ & $15(26.8)$ & $41(73.2)$ & 4.313 & 0.038 \\
\hline \multicolumn{5}{|l|}{ If yes } \\
\hline Laboratory confirmed case of 2019-n-COV $(n=47)$ & $13(27.7)$ & $34(72.3)$ & 0.114 & 0.736 \\
\hline $\begin{array}{l}\text { Person who is under investigation for 2019-nCOV while } \\
\text { that person was ill }(n=9)\end{array}$ & $2(22.2)$ & $7(77.8)$ & & \\
\hline \multicolumn{5}{|l|}{ If yes, in which setting } \\
\hline $\begin{array}{l}\text { While taking samples/ other investigations } \\
\qquad(n=1)\end{array}$ & $0(0.0)$ & $1(100.0)$ & - & 1.000 \\
\hline Clinical care of case (among HCW) $(n=14)$ & $3(21.4)$ & $11(78.6)$ & - & 0.736 \\
\hline Housekeeping (Hospital) $(n=2)$ & $0(0.0)$ & $2(100.0)$ & - & 1.000 \\
\hline $\begin{array}{l}\text { Caregiver of the case (Specify details of case) } \\
\qquad(n=15)\end{array}$ & $4(26.7)$ & $11(73.3)$ & - & 1.000 \\
\hline $\begin{array}{l}\text { Visit to a place where } 2019-n-C O V \text { cases are treated or } \\
\text { sampled (specify details) }(n=9)\end{array}$ & $5(55.6)$ & $4(44.4)$ & - & 0.048 \\
\hline Others, specify ( $n=13$ ) & $3(23.1)$ & $10(76.9)$ & - & 1.000 \\
\hline Not known $(n=7)$ & $0(0.0)$ & $7(100.0)$ & - & 0.171 \\
\hline
\end{tabular}




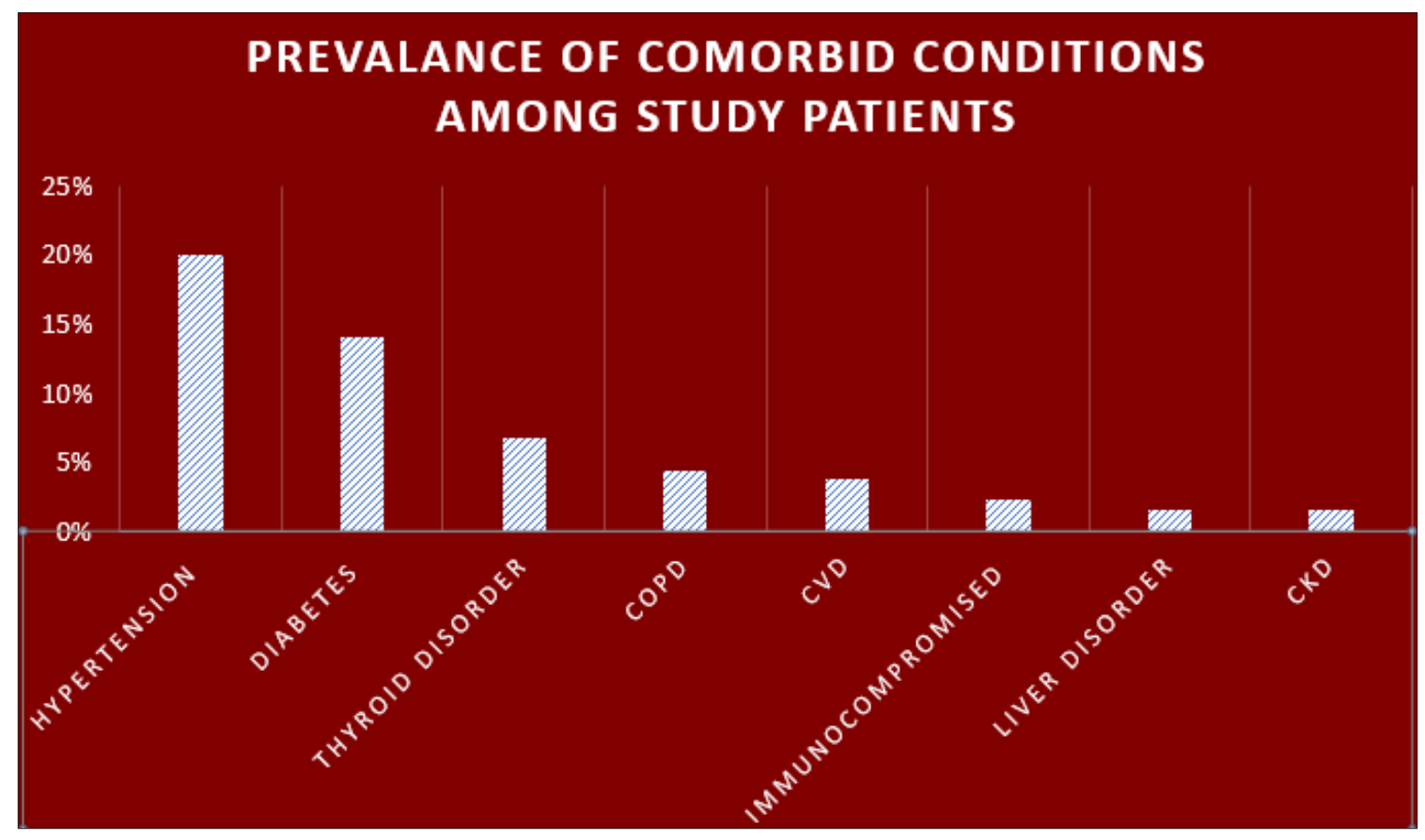

Figure I.Prevalence of comorbid conditions among I35 study RT-PCR confirmed study patients

*COPD= Chronic Obstructive Pulmonary Disease, $C K D=$ Chronic Kidney Disease, CVD=Cardiovascular disease

A significant difference was found in more than half of the patients with and without comorbid conditions who visited a place where 2019-nCOV cases were being treated or sampled $(p=0.048)$. Close contact with a known COVID-19 patient in $47(34.8 \%)$ subjects was the most common exposure characteristic, nine (6.7\%) patients were in contact with an ill patient undergoing investigation for COVID-19, 15 (11.1\%) were caregivers of the case and 14 (10.3\%) were among Health Care Workers (HCW). There were a few (5 (3.7\%) patients who gave a history of travel outside India in the past one month (Table 3).

Among the symptomatic, the presenting symptoms at the time of admission were fever $(n=77 ; 57 \%)$ in majority of patients, cough ( $n=58 ; 42.9 \%)$, fatigue ( $n=57 ; 42.2 \%$ ) breathlessness ( $n=38 ; 28.1 \%)$, headache ( $n=36 ; 26.7 \%$ ) and sore throat $(n=33 ; 24.4 \%)$. These and all the rest of the symptoms of these patients are given in Table 1 . On comparing patients with and without comorbidity, it was found that fatigue, headache, nausea, or vomiting were significantly associated with patients having comorbidity, having $\mathrm{p}$-value $<0.05$. Abnormal chest auscultation ( $\mathrm{n}$ $=12$ ) and abnormal chest X-ray findings ( $n=16$ ) were seen more in patients with comorbidity as compared to others. An important finding in the study is that majority of the asymptomatic patients ( $n=29 ; 21.5 \%)$ were those who have no comorbidity ( $n=24 ; 82.8 \%$ ) with $p$-value of 0.013 (Table 1).

Various comorbidities were present among 135 cases on admission, as revealed by the patient's self-report. Thirty Two (23.7\%) patients reported having at least one comorbidity and $14(10.4 \%)$ patients had more than one comorbidity. The prevalence of specific comorbidities was as follows: hypertension $(27 ; 20 \%)$, diabetes (19; $14.1 \%)$, chronic obstructive pulmonary disease $(6 ; 4.4 \%)$, cardiovascular diseases $(5 ; 3.7 \%)$, liver disorder $(2 ; 1.5 \%)$, chronic kidney diseases ( $2 ; 1.5 \%)$, immunodeficiency $(3$; $2.2 \%)$, and thyroid disorder $(9 ; 6.7 \%)$. None of the cases had malignancy (Figure 1).

When the patients were enquired about the feeling when they got to know about the COVID-19 positive status, most of them felt worried ( $n=56 ; 41.5 \%)$ and anxious ( $n$ $=36 ; 26.7 \%)$. Patients without comorbidity were more likely to have a bad emotional status (83.3\%) compared to those who reported a pre-existing disease $(16.7 \%)$ and this difference was statistically significant ( $p=0.055)$; also their family's response was supportive (60\%) as compared to those with comorbid conditions (40\%), however, p-value was insignificant. Some participants reported having faced discrimination or changed attitude of their family members after revealing their COVID-19 positive status ( $n=29$; $21.5 \%$ ), and this difference was statistically significant ( $p$ $=0.022$ ). More than half of the patients (52.6\%) faced discrimination or found a change in the attitude of their neighbours however, the difference was not statistically significant ( $p=0.093$ ) (Table 2).

More than half of the patients ( $n=85 ; 62.9 \%$ ) reported use of medicines such as AYUSH medicines (28.1\%), vitamin-C medicines (25.2\%), multivitamins (17.8\%), HCQ (10.4\%) etc. to protect themselves from contracting coronavirus infection (Table 1). 
Table 4.Comparison of Main Characteristics of Previous Studies with the Present Study

\begin{tabular}{|c|c|c|c|c|c|c|}
\hline \multirow{2}{*}{ Study (Total Sample Size) } & \multirow{2}{*}{$\begin{array}{c}\text { Mean Age } \\
\text { (Years) }\end{array}$} & \multicolumn{3}{|c|}{ Symptoms (\%) } & \multicolumn{2}{|c|}{ Comorbidities (\%) } \\
\hline & & Fever & Cough & Fatigue & Hypertension & Diabetes \\
\hline Wang et al. $(n=138)^{2}$ & 56.0 & 98.6 & 59.4 & 69.6 & 31.2 & 10.1 \\
\hline Guan et al. $(n=1099)^{5}$ & 47.0 & 87.9 & 67.7 & 38.1 & 14.9 & 7.4 \\
\hline Richardson et al. $(n=5700)^{6}$ & 63.0 & 3.7 & 59.4 & - & 56.6 & 33.8 \\
\hline Huang et al. $(n=41)^{8}$ & 49.0 & 98.0 & 76.0 & 44.0 & 15.0 & 20.0 \\
\hline Yang et al. $(n=1576)^{9}$ & & 91.3 & 67.7 & 51.0 & 21.1 & 9.7 \\
\hline Chen et al. $(n=99)^{10}$ & 55.5 & 83 & 82 & - & - & 13 \\
\hline Zhang et al. $(n=147)^{11}$ & 57.0 & 91.7 & 75 & 75 & 30.0 & 12.1 \\
\hline Liu et al. $(n=137)^{13}$ & 57.0 & 81.8 & 48.2 & 32.1 & 9.5 & 10.2 \\
\hline Mohan et al. $(n=144)^{14}$ & 40.1 & 17.4 & 34.7 & 1.4 & 2.1 & 11.1 \\
\hline Kishore et al. $(n=206)^{15}$ & 41.94 & 72.6 & 76.8 & 72.2 & 83.3 & 84.2 \\
\hline Current study $(n=135)$ & 41.8 & 57.0 & 42.2 & 42.9 & 20.0 & 14.1 \\
\hline
\end{tabular}

\section{Discussion}

Many studies have shown that pre-existing comorbid conditions are linked with a higher risk of developing more severe COVID-19. In our study also we found that $37.03 \%$ of COVID-19 positive cases had comorbidities, mostly in the older age group of more than 46 years. The present study documents the presence of at least one comorbidity in $23.7 \%$ of the subjects, and the most prevalent comorbidity was hypertension (20\%), followed by diabetes mellitus (14.1\%) which is comparable to another study conducted nationwide by Guan et al. in which $25.1 \%$ people had at least one comorbidity. ${ }^{5}$ Various studies showed that hypertension and diabetes were highly prevalent in COVID-19 positive cases and this pattern was similar to our data (Table 4)..$^{5,6,8,9,11,15}$ In our study, when cases with and without comorbidity were compared according to age, the population with more than 46 years of age with comorbid conditions were more which was statistically significant, in contrast to the subjects in the age group between 31 and 45 years wherein majority of the positive cases were not having any pre-existing condition.

In the present study, a significantly less proportion of patients were asymptomatic (21.5\%), however, two studies from north India reported having almost half of the patients who had no symptom.12,13 We found that the most prevalent symptoms were fever (57.03\%), fatigue (42.9\%), and cough (42.2\%). A similar picture has been seen in many other studies, compared to the previously published studies from other countries and India, wherein almost every study reported these three symptoms, fever, dry cough, and fatigue as the most commonly reported symptoms (Table 4). 2,4-13

In the present study, around $41.5 \%$ of the participants reported having contact with a COVID-19 positive case which was much higher when compared to another study from North India carried out by Mohan et al. in the initial phase of lockdown. ${ }^{14}$ They reported only $4.9 \%$ of the patients who had close contact with COVID-19 positive cases. Among HCW, 10.4\% reported having contracted the infection while giving clinical care to COVID-19 positive cases while another Indian study reported a very low percentage of $1.4 \% .^{14}$

Since COVID-19 is a new disease, and people are often afraid of the unknown, a study from India reported fear related to the COVID-19 virus in $78.9 \%$ of the healthy population. ${ }^{15}$ People hide the illness due to social stigma and to avoid discrimination which discourages them from seeking health care immediately. ${ }^{15-18}$ COVID-19 patients were asked a few questions regarding the stigma. Many patients without comorbidity (83.3\%) were sad after knowing their COVID-19 status in contrast to the patients with comorbidity (16.7\%), and this difference was statistically significant $(p=0.05)$. When similar questions were asked about their family members, the response was mainly supportive (60\%) and worried (60.4\%) among patients without comorbid conditions in contrast to subjects with comorbidity, and this difference was not statistically significant.

Thirty eight (28.14\%) patients reported use of AYUSH interventions as prophylactic medicines, 24 patients reported use of Ayurvedic medicines (Ayush Kwath, Chyawanprash), and 19 patients reported use of Unani medicines (Khamira Marwareed, Tiryaq Arba, Unani Joshanda) as prophylaxis. In addition to these medicines, 11 patients reported the use of some homemade preparation such as use of warm water, haldi milk, ginger juice with honey, Gilo (Tinospora cordifolia), Ashwagandha (Withania somnifera), Kalongi 
(Nigella sativa), and Senna makki (Cassia angustifolia). (Table 1) On the basis of this study, it can be concluded that there has been an increase in the use of AYUSH medicines when compared to a previous online survey during the early period of lockdown in India which reported the use of Unani prophylaxis and ayurvedic immune boosters by only $4.5 \%$ and $2.9 \%$ of the population respectively. ${ }^{19}$

\section{Limitations of the Study}

The study lacked a negative RT-PCR control group that could better interpret the association in terms of clinical findings, comorbidity, anxiety, and stigma between the COVID-19 positive and negative groups. This was a single-institution study with possible selection bias, and thus the findings may not be representative of the overall population of COVID-19 positive patients in India.

\section{Source of Funding: Self \\ Conflict of Interest: None}

\section{References}

1. WHO [Internet]. Coronavirus Disease (COVID-19) [cited 2020 Jan 13]. Available from: https://covid19.who.int/

2. Wang D, Hu B, Hu C, Zhu F, Liu X, Zhang J, Wang B, Xiang $\mathrm{H}$, Cheng Z, Xiong Y, Zhao Y, Li Y, Wang X, Peng Z. Clinical Characteristics of 138 Hospitalized Patients With 2019 Novel Coronavirus-Infected Pneumonia in Wuhan, China. JAMA. 2020; 323(11):1061-9. [PubMed] [Google Scholar].

3. Biswas M, Rahaman S, Biswas TK, Haque Z, Ibrahim B. Association of Sex, Age, and Comorbidities with Mortality in COVID-19 Patients: A Systematic Review and Meta-Analysis. Intervirology. 2021;64:36-47. doi: https://doi.org/10.1159/000512592. [PubMed] [Google Scholar].

4. National Centre for Disease Control [Internet]. Form A. Available from: https://ncdc.gov.in/WriteReadData/ I892s/392888771580884195.pdf

5. Guan WJ, Liang WH, Zhao Y, Liang HR, Chen ZS, Li YM, Liu XQ, Chen RC, Tang CL, Wang T, Ou CQ, Li L, Chen PY, Sang L, Wang W, Li JF, Li CC, Ou LM, Cheng B, Xiong S, Ni ZY, Xiang J, Hu Y, Liu L, Shan H, Lei CL, Peng YX, Wei L, Liu Y, Hu YH, Peng P, Wang JM, Liu JY, Chen Z, Li G, Zheng Z, Qiu SQ, Luo J, Ye CJ, Zhu SY, Cheng LL, Ye F, Li SY, Zheng JP, Zhang NF, Zhong NS, He JX, China Medical Treatment Expert Group for COVID-19. Comorbidity and its impact on 1590 patients with Covid-19 in China: A Nationwide Analysis. Eur Respir J. 2020 May 14;55(5):2000547. doi: https://doi.org/10.1183/13993003.00547-2020. [PubMed] [Google Scholar].

6. Richardson S, Hirsch JS, Narasimhan M, Crawford JM, McGinn T, Davidson KW, Northwell COVID-19 Research Consortium. Presenting Characteristics, Comorbidities, and Outcomes Among 5700 Patients Hospitalized
With COVID-19 in the New York City Area. JAMA. 2020;323(20):2052-9. doi: https://doi.org/10.1001/ jama.2020.6775. [PubMed] [Google Scholar].

7. Zhou F, Yu T, Du R, Fan G, Liu Y, Liu Z, Xiang J, Wang Y, Song B, Gu X, Guan L, Wei Y, Li H, Wu X, Xu J, Tu S, Zhang $\mathrm{Y}$, Chen $\mathrm{H}, \mathrm{Cao} \mathrm{B}$. Clinical course and risk factors for mortality of adult inpatients with COVID-19 in Wuhan, China: a retrospective cohort study. Lancet. 2020;395(10229):1054-62. [PubMed] [Google Scholar].

8. Huang C, Wang Y, Li X, Ren L, Zhao J, Hu Y, Zhang L, Fan G, Xu J, Gu X, Cheng Z, Yu T, Xia J, Wei Y, Wu W, Xie X, Yin W, Li H, Liu M, Xiao Y, Hong G, Guo L, Xie J, Wang G, Jiang R, Gao Z, Jin Q, Wang J, Cao B. Clinical features of patients infected with 2019 novel coronavirus in Wuhan, China. Lancet. 2020;395(10223):497-506. [PubMed] [Google Scholar].

9. Yang J, Zheng Y, Gou X, Pu K, Chen Z, Guo Q, Ji R, Wang $\mathrm{H}$, Wang $\mathrm{Y}$, Zhou Y. Prevalence of comorbidities and its effects in patients infected with SARS-CoV-2: a systematic review and meta-analysis. Int J Infect Dis. 2020;94:91-5. [PubMed] [Google Scholar].

10. Chen N, Zhou M, Dong X, Qu J, Gong F, Han Y, Qiu Y, Wang J, Liu Y, Wei Y, Xia J, Yu T, Zhang X, Zhang L. Epidemiological and clinical characteristics of 99 cases of 2019 novel coronavirus pneumonia in Wuhan, China: A descriptive study. Lancet. 2020;395(10223): 507-13. [PubMed] [Google Scholar].

11. Zhang JJ, Dong X, Cao YY, Yuan YD, Yang YB, Yan YQ, Akdis CA, Gao YD. Clinical characteristics of 140 patients infected with SARS-CoV-2 in Wuhan, China. Allergy. 2020;75:1730-41. [PubMed] [Google Scholar].

12. Gupta N, Agrawal S, Ish P, Mishra S, Gaind R, Usha G, Singh B, Sen MK, Safdarjung Hospital Covid Working Group. Clinical and epidemiologic profile of the initial COVID-19 patients at a tertiary care centre in India. Monaldi Arch Chest Dis. 2020;90:1294. [PubMed] [Google Scholar].

13. Liu K, Fang YY, Deng $Y$, Liu W, Wang MF, Ma JP, Xiao W, Wang YN, Zhong MH, Li CH, Li GC, Liu HG. Clinical characteristics of novel coronavirus cases in tertiary hospitals in Hubei Province. Chin Med J. 2020 May 5;133(9):1025-31. [PubMed] [Google Scholar].

14. Mohan A, Tiwari P, Bhatnagar S, Patel A, Maurya A, Dar L, Pahuja S, Garg R, Gupta N, Sahoo B, Gupta R, Meena VP, Vig S, Pandit A, Mittal S, Madan K, Hadda V, Dwivedi T, Choudhary A, Brijwal M, Soneja M, Guleria R, Ratre B, Kumar B, Bhopale S, Panda S, Singh AR, Singh S, Wundavalli L. Clinico-demographic profile \& hospital outcomes of COVID-19 patients admitted at a tertiary care centre in north India. Indian J Med Res. 2020;152(1):61-9. doi: https://doi.org/10.4103/ijmr. IJMR_1788_20. [PubMed] [Google Scholar].

15. Kishore J, Bharti A, Heena, Yadav G, Gupta N, Meena 
R. Risk Factors of COVID-19 among Patients Attending a Tertiary Care Centre in Delhi: A Case Control Study. Epidem Int. 2020;5(4):5-11. [Google Scholar].

16. Heena, Nazli T, Grover S, Kishore J. Covid-19 Pandemic and "Feeling Depressed": An Online Survey. Epidem Int. 2020;5(2):27-31. [Google Scholar].

17. World Health Organisation [Internet]. Social Stigma associated with COVID-19. [cited 2020 Aug 15]. Available from: https://www.who.int/docs/defaultsource/coronaviruse/covid19-stigma-guide.pdf

18. Kishore J, Anand T, Heena, Nazli T. Depression during COVID-19 Pandemic in India: Findings from an Online Survey. Int J Preven Curat Comm Med 2020; 6(2): 16-21.

19. Nazli T, Heena, Raheem A, Kishore J. Perceptions and Practices of the Adult Population in Response to SARSCoV-2 Pandemic in India. Epidem Int. 2020;5(2):10-16. [Google Scholar]. 